\title{
The Two Faces of Teacher Candidates' Portfolio Experiences: Tradition and Facebook ${ }^{*}$
}

\author{
Hanife Gulhan Orhan Karsak* \\ Department of Education Sciences, Faculty of Science Literature, Kirklareli University, Turkey
}

Copyright $(2016$ by authors, all rights reserved. Authors agree that this article remains permanently open access under the terms of the Creative Commons Attribution License 4.0 International License

\begin{abstract}
Exploring the effectiveness of facebook in the process of preparing portfolio, it will be significant to profit by teacher candidates' experiences on facebook and traditional environments. Therefore in this phenomenon study to fathom of the portfolio experiences on both environments is intended. In this regard the opinions of the volunteers who have continued portfolio studies every week, were taken from utilizing four semi-structured open-ended questions. In consequence they are in the pedagogical formation program, ten female and five male in both environments, in total thirty participants. Data were collected in writing in fifty minutes, analyzed via Nvivo 10, presented with mind maps. Participants think that facebook environment is compared to other social networks easy to reach, actual, the best known environment, gives opportunity to add various types of files, facilitates sharing independent of time and place and creating an archive, although they stated that the participants who use the environment for the first time in an instruction process, don't take responsibility and despite warnings. For traditional environment, they believe that develop a high level of consciousness of communication, sharing, task and responsibility. However they express the lack of opportunities to see sharings instantly and to make peer review between groups.
\end{abstract}

Keywords Portfolio, Facebook, Traditional, Social Network, Experiences

\section{Introduction}

As of the first quarter of 2016, Facebook had 1.65 billion monthly active users. Active users are those which have logged in to Facebook during the last 30 days [17]. So Facebook is still the most popular social network worldwide. With the smart phone shortcut button, students usually enter the Facebook most of times of a day. In this context, the Facebook environment which is so much enjoyable for students, would be wise to make use of the productive and enjoyable learning and evaluation processes. One of the usages of the Facebook for learning and evaluation processes is e-portfolios.
Paulson, Paulson and Carol [16] defines portfolio as a purposeful collection of students' products of learning that exhibits the student's efforts, progress, and achievements in one or more areas. The collection must include student participation in selecting contents, the criteria for selection, the criteria for judging merit, and evidence of students' reflections.

Some of the advantages of the portfolio are questioning, self-assessment, transferring of information for students, Conscious of the responsibility for monitoring the student's cognitive development for teachers [4]. Also portfolio recognizes and encourages the autonomous and reflective learning, based in the real experience of the learner and connects theory and practice, allows a range of learning styles [18]. Erdogan and Yurdabakan [9] stress that portfolios guide the students to create various types of more authentic work and urge them to be more creative; also portfolio assessment gives the learners more freedom and provide facilities to development and improvement of their higher order thinking skills and meta-cognitive strategies.

In the recent years electronic environments such as facebook, blogs, web pages, softwares are integrated with portfolio to increase the benefits which are mentioned above. Barrett[2] describes electronic portfolios as: '(those that make) use of electronic technologies that allow the portfolio developer to collect and organize artefacts in many formats (audio, video, graphics, and text). A standards-based electronic portfolio uses hypertext links to organize the material to connect artefacts to appropriate goals or standards... An electronic portfolio is not a haphazard collection of artefacts (i.e., a digital scrapbook or multimedia presentation) but rather a reflective tool that demonstrates growth over time'. Mobarhan et al. [15] signed many advantages of e-portfolio such as self-documentation, informativeness, information sharing, social interaction, entertainment, convenience utility. Using facebook as an electronic portfolio has also advantages. In this regard, Barrot [3] found that Facebook-based e-portfolio had a positive impact on students' writing practices, making it a viable tool for e- portfolio assessment. Besides that report on ePortfolio evaluations show that students were only moderately convinced that their e-portfolios were helpful and only a minority of students planned to continue using 
them after course completion. These findings represent a serious challenge to the claim that ePortfolios are student owned and supportive of deep and reflective learning ([19] \& [6]; cited in [17]).

Otherwise Aydin [1] mentioned some practical and logistical problems related to e-portfolios can arise. One of them is software development. The instruction of a software is not given to most of students. Additionally there is not constant possibility of purchasing e-portfolio software due to economic conditions. In this condition, the solution that comes to mind is facebook closed group. It is frequently used in daily life. So as Aydin [1] expressed facebook may therefore present ways for teachers and learners to bypass the mentioned problems, as there is no need for special instruction or purchase to use facebook. Facebook may meet teachers' and learners' pedagogical expectations for e-portfolios. So there are little researches that examined and got the experiences in the environment. In this context, learning and reviewing the experiences of traditional and facebook environments is important to discover the advantages and limited sides of the facebook as e-portfolio. According to the reasons which are mentioned above, the aim of this research is to examine the teacher candidates' experiences of two types of portfolio as in facebook and traditional.

\section{Method}

Phenomenology studies are accomplished in order to define the common meaning of the experiences of a few people related to a phenomenon or a concept [8]. In this regard, because of exploring the effectiveness of facebook in the process of preparing portfolio, it will be significant to profit by students' experiences on facebook and traditional environments. Therefore in this phenomenon study to fathom of the portfolio experiences on both environments is intended. The phenomenon study has been selected in order to investigate what, why and how are the similarities and differences between the experiences and in the experiences of every teacher candidates. Wherefore the researcher gives lectures, Kirklareli University has been selected. In this regard the opinions of the volunteers who have continued portfolio studies every week, were taken from utilizing four semi-structured open-ended questions. Data were collected in writing in fifty minutes and were given personnel numbers. Data were analyzed via Nvivo 10 with have been created categories and themes. Findings were presented with mind maps.

\section{Participants}

In consequence of the participants are in the pedagogical formation program, they are identified with purposeful sampling. This sampling method was followed in order to meet certain predetermined criteria[21]. The ages of the participants within the group heterogeneous between twenty two and thirty five. Ten females and five males in both environments, in total thirty participants.

\section{Findings}

\subsection{Positive sides of the facebook environment as portfolio experience}

The mind map of teacher candidates regarding the positive sides of the facebook as portfolio experiences is presented in Figure 1.

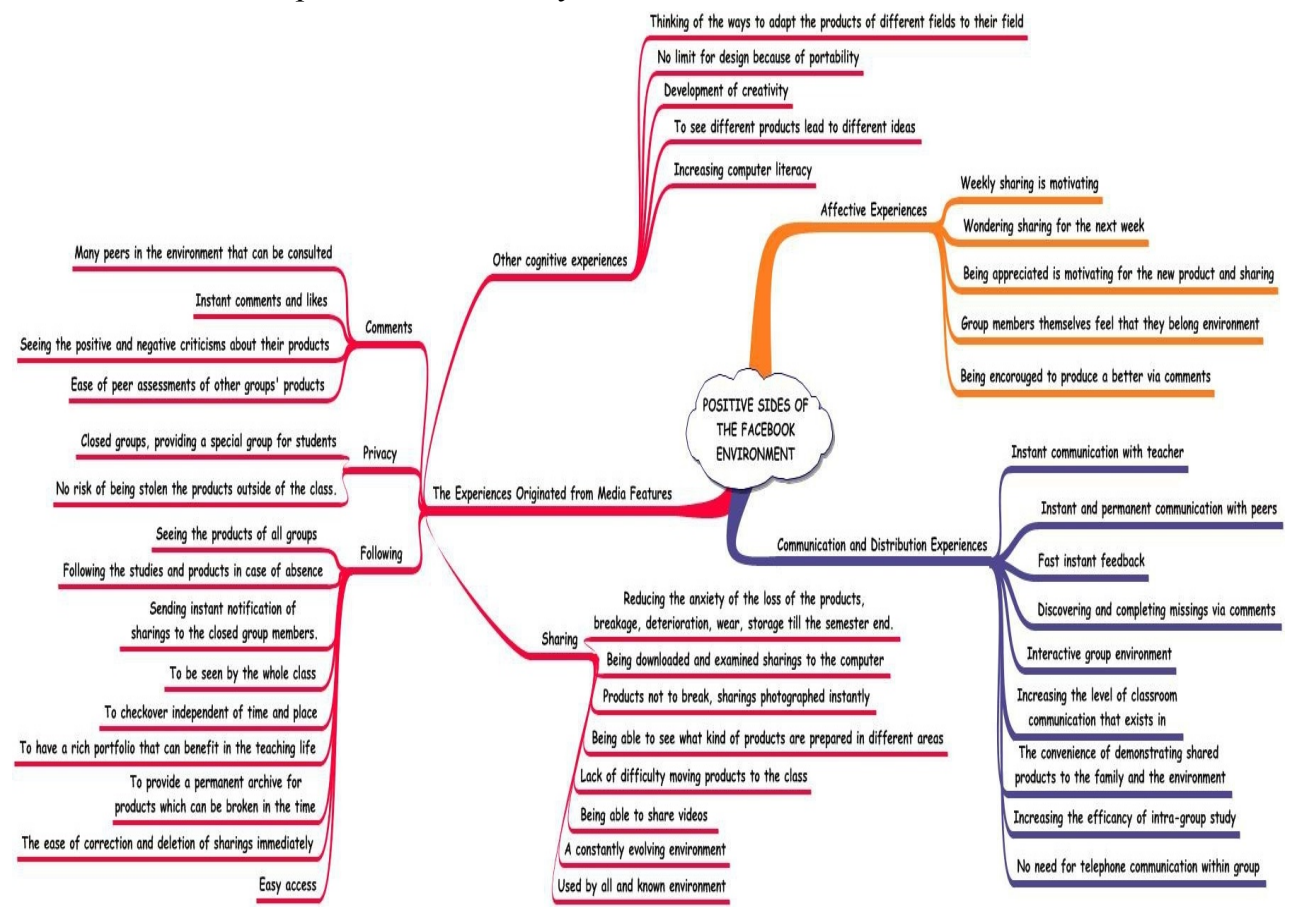

Figure 1. Positive sides of the facebook environment 
As seen in Figure 1, most of teacher candidates stated the positive sides of the facebook regarding the communication and distribution experiences as fast instant feedback, instant communication with teacher, instant and permanent communication with peers, discovering and completing meetings via comments, interactive group environment, increasing the level of classroom communication that exists in, the convenience of demonstrating shared products to the family and the environment, increasing the efficacy of intra-group study, no need for telephone communication within group. A stunning opinion regarding these experiences is as follows:

F1: There were people to consult when could not decide how to prepare material. I communicated quick, practical and without the need of telephone with the members of my group.

On the other hand, teacher candidates emphasized the positive sides of the facebook regarding the affective expressions as wondering sharing for the next week, being encouraged to produce a better via comments, being appreciated is motivating for the new product and sharing, group members themselves feel that they belong to environment. A stunning opinion regarding these experiences is as follows:

F1: I felt myself like I belonged there.

F15: My product that I did with my group, did not like much but my friends in the facebook environment encouraged me with nice comments.

Additionally, teacher candidates signed the positive sides of the facebook for the experiences originated from media features regarding sharing as a constantly evolving environment, used by all and known environment, products not to break and sharings photographed instantly; comments as ease of peer assessments of other groups' products, seeing the positive and negative criticisms about their products; privacy as closed group providing a special group for students; following as to have a rich portfolio that can benefit in the teaching life, to check over in independent time and place; other cognitive experiences as to see different products lead to different ideas, development of creativity. A stunning opinion regarding these experiences is as follows:

F15: The products that we made, broke and lost after a time passed but in facebook sharing as photos were benefitted us for permanency. Also having a rich activity and products archive is a big gain for me that I can look and benefit in my teaching life.

\subsection{Negative and limited sides of the facebook environment as portfolio experience}

The mind map of teacher candidates regarding the negative and limited sides of the facebook as portfolio experiences is presented in Figure 2.

As seen in Figure 2, most of teacher candidates expressed the negative sides of the facebook regarding the communication and distribution experiences as lack of everyone's internet connection, intragroup conflict, lack of access to group when the internet and telephone problem occurs, negative comments reducing students' interest to the course. A stunning opinion regarding these experiences is as follows:

F9: All of our friends did not have internet connection so they could not enter facebook enough.

In addition, teacher candidates voiced the negative sides of the facebook for the media features welded experiences regarding sharing as the error problem in uploading files above a certain capacity, non-computer and non-smart phone cannot reach environment instantly; following as the necessity of using and following up the facebook page; comments as followings by teacher effect the comments.

F4: The participant must be a user who use and follow facebook well. F15: An error was experienced in uploading files over a certain capacity.

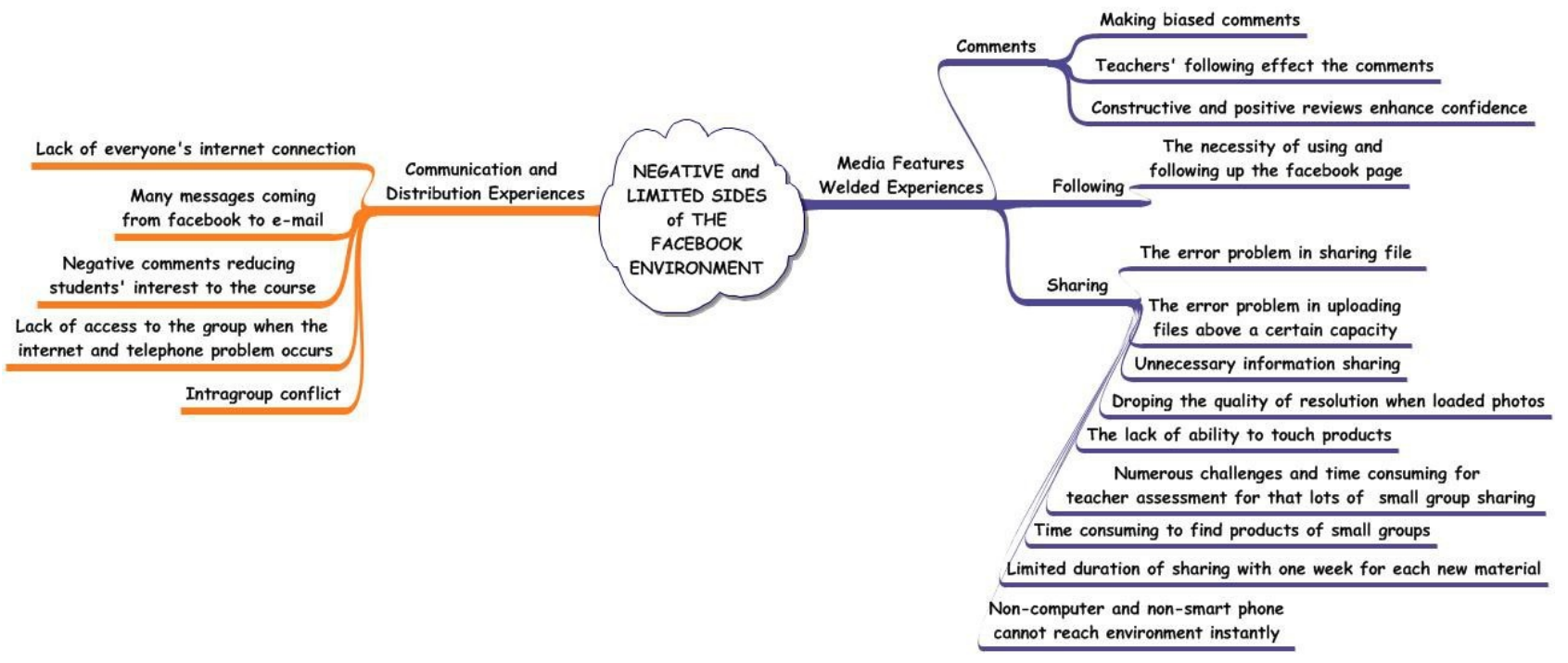

Figure 2. Negative and limited sides of the facebook environment 


\subsection{Positive sides of the traditional environment as portfolio experience}

The mind map of teacher candidates regarding the positive sides of the traditional environment as portfolio experiences is presented in Figure 3.

As seen in Figure 3, most of teacher candidates stated the positive sides of the traditional environment regarding the affective experiences as increased confidence, the sense of real feelings and thoughts. A stunning opinion regarding these experiences is as follows:

T12: We were better able to sense the real thoughts and feelings.

Otherwise, teacher candidates expressed the positive sides of the traditional environment for the environment features welded experiences regarding comments as no lower level comments; following as a concrete archive at one's elbow; other cognitive experiences as memorability, detailed check over facilities. A stunning opinion regarding these experiences is as follows:

T12: The advantages of the traditional environment were permanency, which could be examined in more detail and no bad comments.

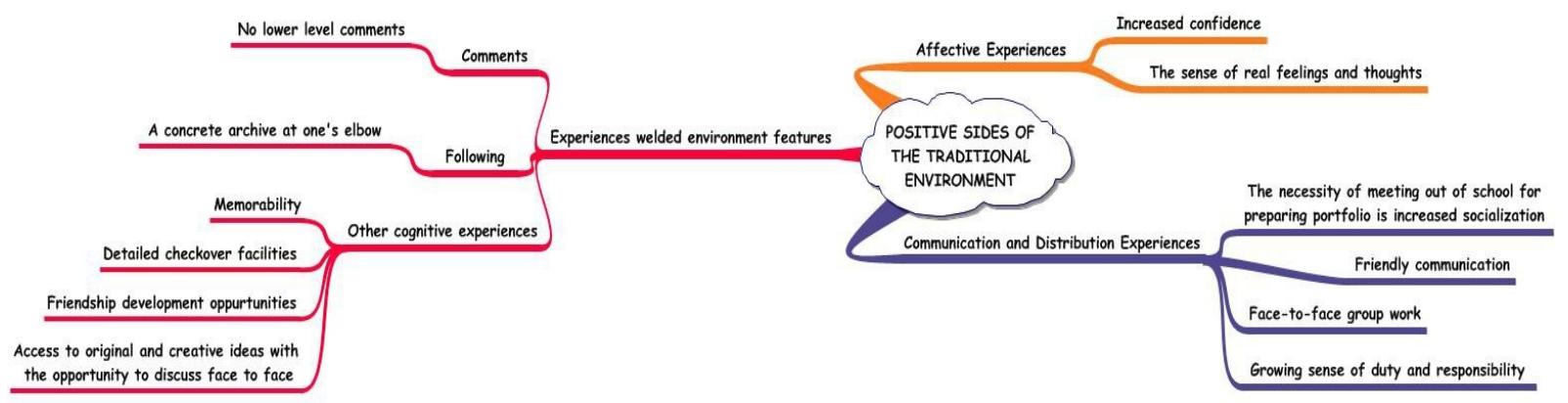

Figure 3. Positive sides of the traditional environment

\subsection{Negative and limited sides of the traditional environment as portfolioexperience}

The mind map of teacher candidates regarding the negative and limited sides of the traditional environment as portfolio experiences is presented in Figure 4.

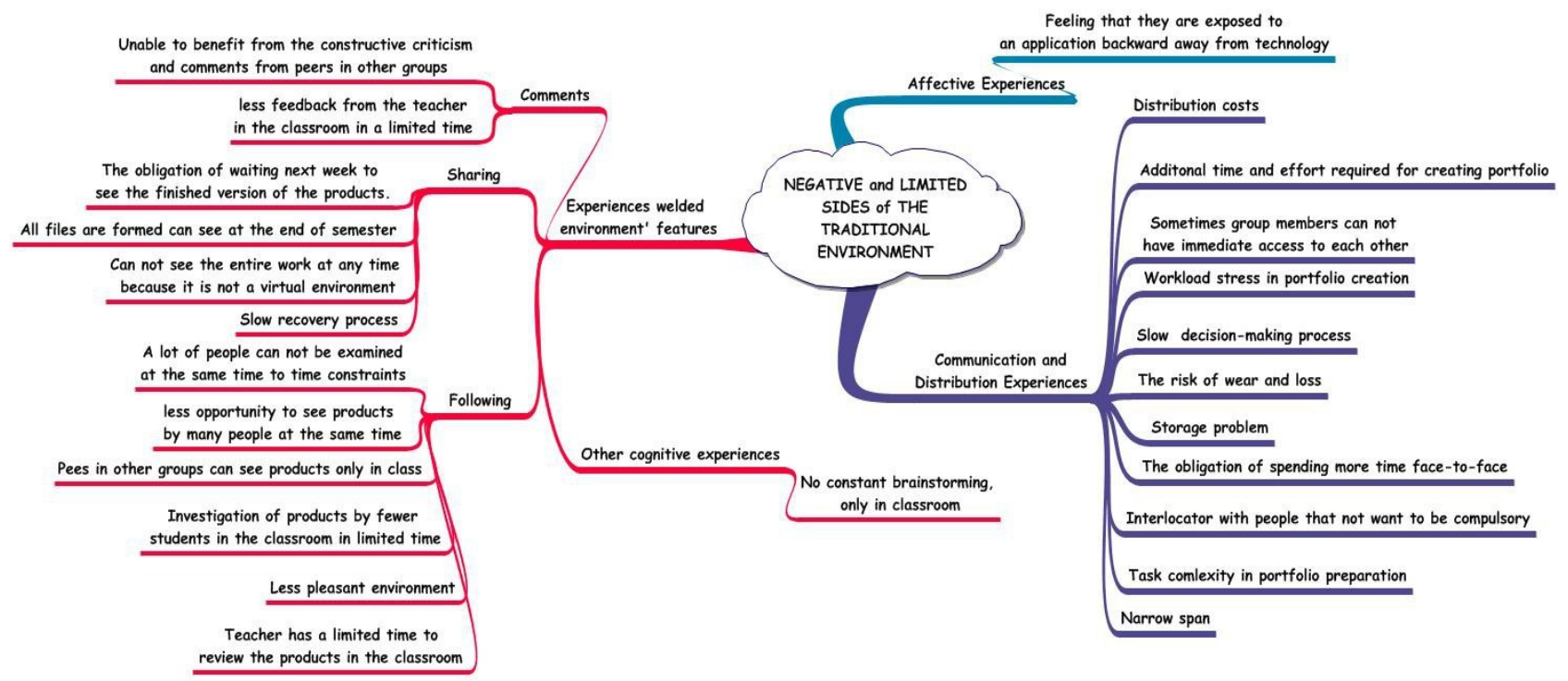

Figure 4. Negative and limited sides of the traditional environment 
As seen in Figure 4, most of teacher candidates stated the negative and limited sides of the traditional environment regarding the affective experiences as feeling that they are exposed to an application backward away from technology. A stunning opinion regarding these experiences is as follows:

T15: Preparing a portfolio in traditional environment had much more workload like printing, sorting. This study type was an old activity. I think it was not appropriate for technological development of nowadays.

On the other hand, teacher candidates pointed out the negative and limited sides of the traditional environment regarding the communication and distribution experiences as the obligation of spending more time face-to-face, task complexity in portfolio preparation, narrow span, the risk of wear and loss, slow decision-making process. A stunning opinion regarding these experiences is as follows:

T12: It had a narrow span. That we did not want to work with people face to face, we have to be addressed.
Additionally, teacher candidates expressed the negative and limited sides of the traditional environment for the environment features welded experiences regarding comments as less feedback from the teacher in the classroom in a limited time; following as peers in other groups can be seen products only in classroom; sharing as slow recovery process; other cognitive experiences as no constant brainstorming, only in classroom. A stunning opinion regarding these experiences is as follows:

T4: Instructor evaluated the products in a limited time only in classroom. So the students could not get enough feedback.

\subsection{The comparison of the positive sides of the environments}

The mind map of teacher candidates regarding the comparison of the positive sides of the environments as portfolio experiences is presented in Figure 5.

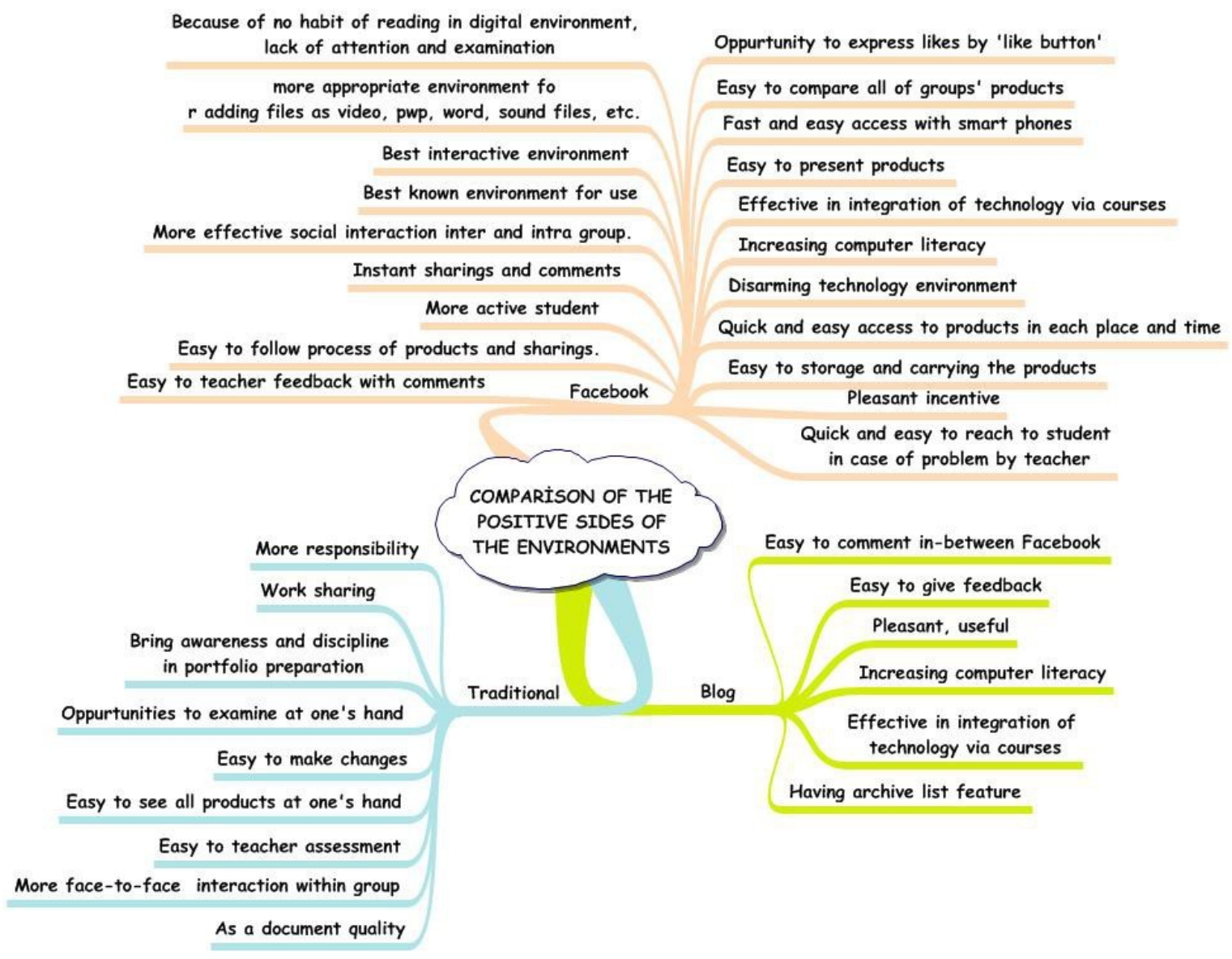

Figure 5. The comparison of the positive sides of the environments 
As seen in Figure 5, when teacher candidates compared the positive sides of the traditional, facebook and blog environment, most of them stated that the positive sides of the traditional environment comparing the other environments more responsibility, work sharing, bring awareness and discipline in portfolio preparation, easy to see all products in one's hand, easy to teacher assessment, more face-to-face interaction within group, a document quality. At the same time, they pointed out the positive sides of the blog environment comparing the other environments easy to comment in-between facebook, easy to give feedback, pleasant and useful, increasing computer literacy, effective in integration of technology via courses, having archive list feature. In addition, they stressed the lots of positive sides of the facebook environment comparing the other environments such as best known environment for using, fast and easy access with smart phones, more appropriate environment for adding various types of files, more active students, instant sharing and comments. A stunning opinion regarding these experiences is as follows:

T6: The products may store as an archive in blog environment.

F13: Students could share products and compare them with other students' products easily. They could express likings with 'like' button. So they could realise the strengths and weaknesses sides of themselves.

F12: The work sharing between the group members were sufficient and brought in joint responsibility.

\subsection{The comparison of the negative and limited sides of the environments}

The mind map of teacher candidates regarding the comparison of the negative and limited sides of the environments as portfolio experiences is presented in Figure 6.

As seen in Figure 6, when teacher candidates compared the negative and limited sides of the traditional, facebook and blog environment, most of them stated that the lots of negative and limited sides of the traditional environment comparing the other environments the difficulty of giving feedback to the students, cost and time consuming, boring, old and tired, products are not visible to other students and not to be criticized by peers efficiently. In the other hand, they signed the negative and limited sides of the blog environment comparing the other environments not having possibilities as facebook, the problem of attaching various types of files, the obligation of facebook entering and membering for making comments, is not known as facebook, lack of accessing via smart phones. In addition, they stated the negative and limited sides of the facebook environment comparing the other environments such as products can solely be seen by closed group' members, lack of accessing to internet connection in every time, bias, likes for not breaking heart, the necessity of opening facebook account. A stunning opinion regarding these experiences is as follows:

F12: It could be biased in facebook environment. The friends did not like indeed but they wrote comments as they liked.

F13: Blog environment has too much advertisements and sharing videos is only can make with a shortcut link which is obtained from other loading sites.

F4: Filing is time consuming in traditional environment. It is difficult to store, transfer and prepare.

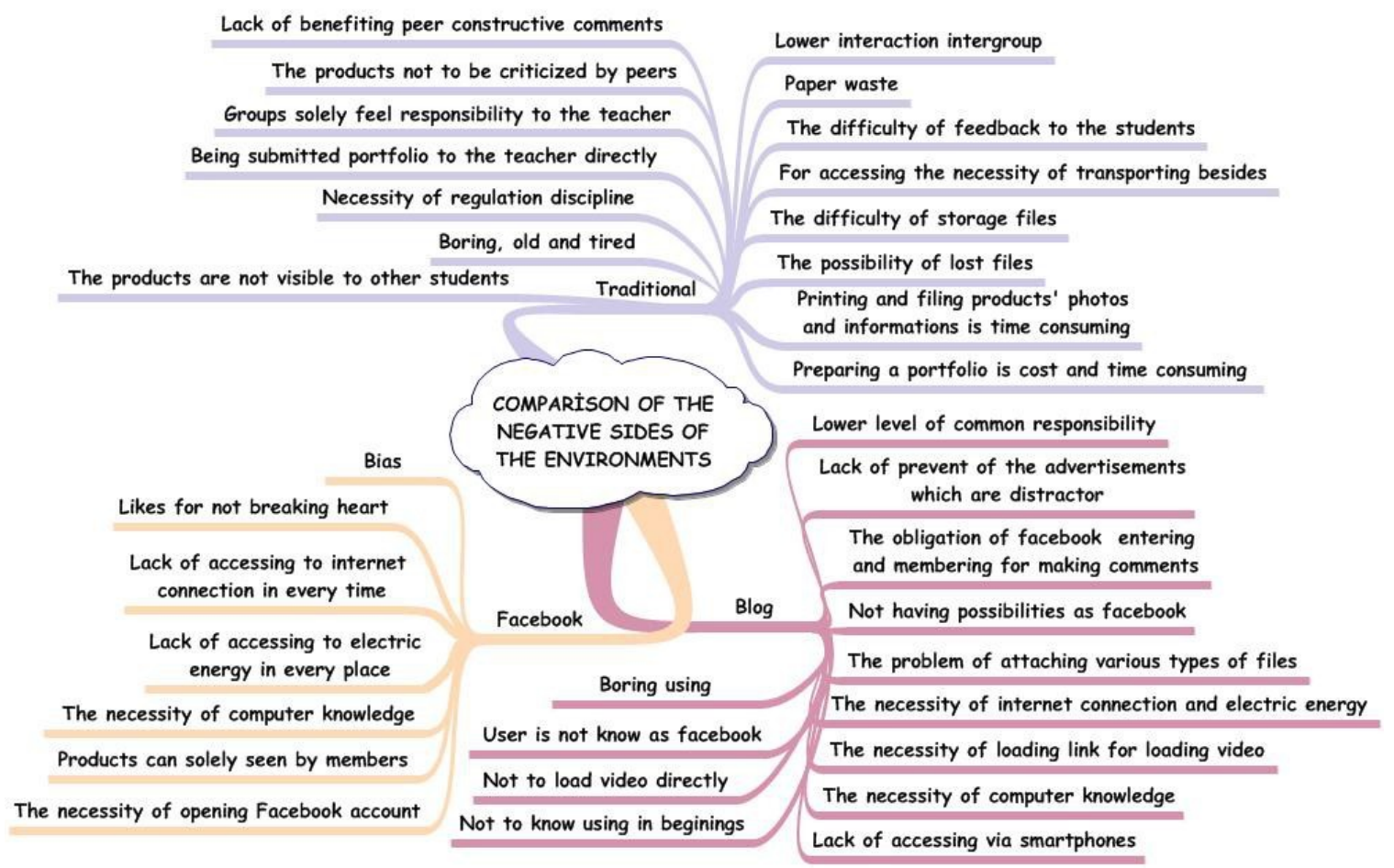

Figure 6. The comparison of the negative and limited sides of the environments 


\subsection{Reasons for choosing the environment}

Although teacher candidates takes place in another portfolio studying, ten of them in other words most of them stated to choose the facebook, three of them stated to choose blog and two of them in other words a few of them stated to choose the traditional environment. In Figure 7, the mind map is seen that they expressed their reasons for choosing the environment.

As seen in Figure 7, teacher candidates stated the reasons for choosing facebook such as quick access to sharing, the possibility of frequently entering because of smart phone' shortcut button to facebook, the comments of teachers and students are motivating, constantly updated and improved environment, the opportunity of instant feedback to the students by teacher. Moreover they expressed the reasons for choosing blog such as being more suitable for writing in the social sciences, easy to following owing to an archive list that classifying by date and topic. Otherwise they signed the reasons for choosing traditional environment such as a better understanding of portfolio preparation and page format of the portfolio, the possibility of examine the portfolio at the hand and the students who are inadequate for using technology do not have problems. A stunning opinion regarding these experiences is as follows:

F11: I choose facebook closed group environment. Because facebook provide to make comments, likes and to see strengths and weaknesses and see products in detail.

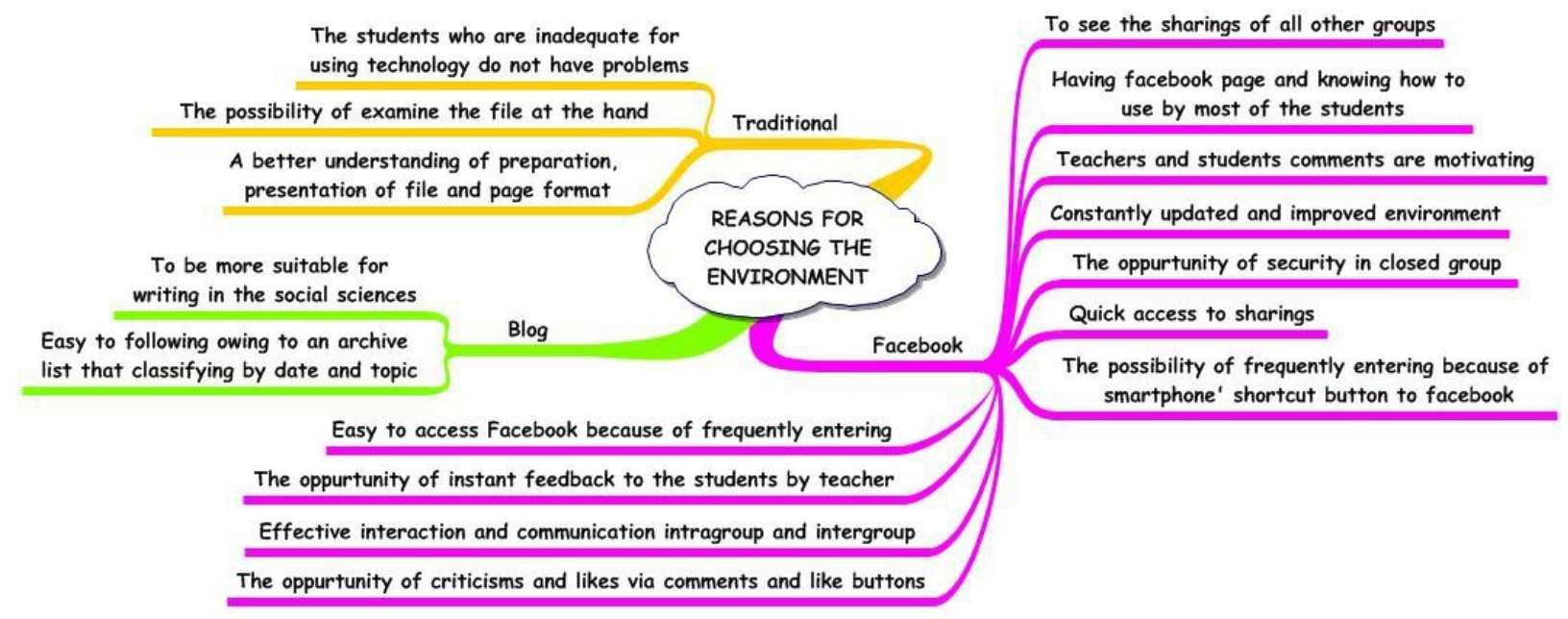

Figure 7. Reasons for choosing the environment

\subsection{Sample activities in the environments}

In Figure 8, the mind map of teacher candidates is seen that they stated the samples of portfolio experiences for their subjects in three environments.

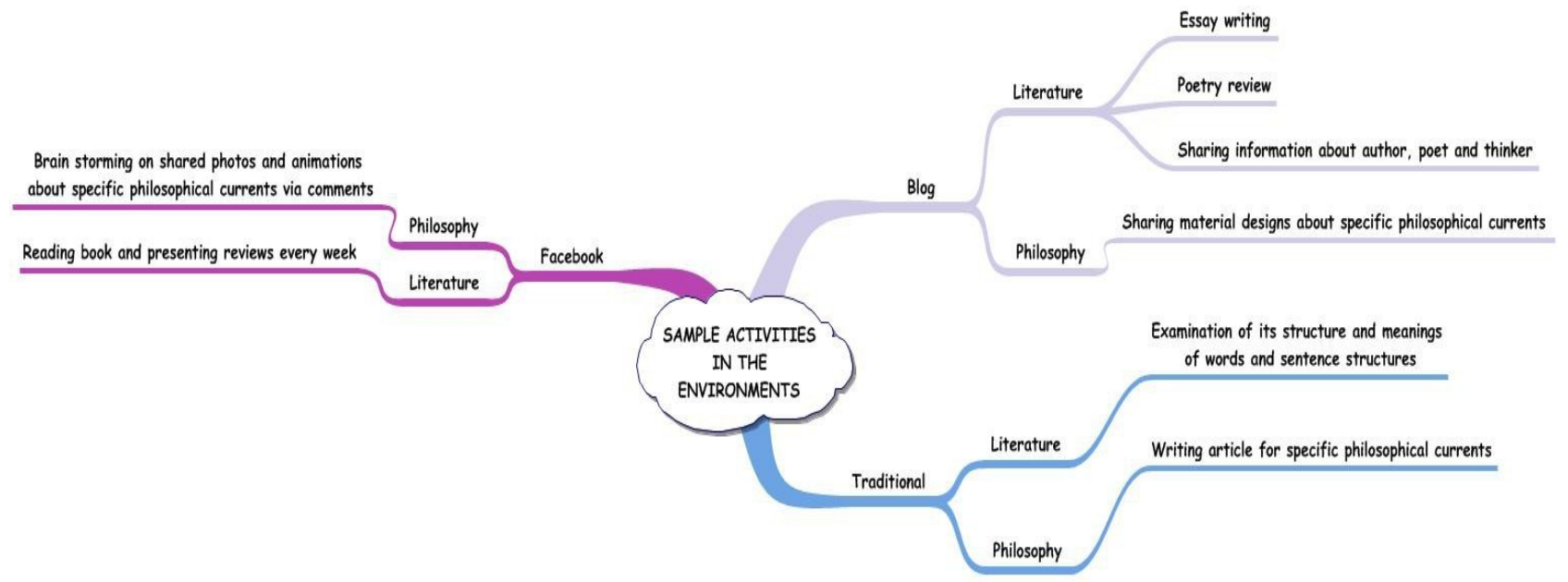

Figure 8. Sample activities in the environments 
As seen in Figure 8, teacher candidates expressed the sample activities in the environments such as for literature essay writing, for philosophy sharing material designs about specific philosophical currents in the blog environment; for literature examination of its structure and meanings of words and sentences structures, for philosophy writing articles for specific philosophical currents in the traditional environment, for literature reading books and presenting reviews every week, for philosophy brain storming on shared photos and animations about specific philosophical currents via comments in the facebook environment.

\section{Discussion, Conclusion and Recommendations}

Teacher candidates expressed more positive sides of the facebook environment comparing to traditional environment as portfolio experiences. These positive sides are superior to traditional, related to comments, sharing, security, following and other cognitive experiences. For comments they stressed the opportunities of seeing the positive and negative criticisms about their products and ease of peer assessment of other groups' products, instant comments and likes. Barrot [3] reached the similar results that Facebook-based e-portfolio had a positive impact on students' writing practices, making it a viable tool for e-portfolio assessment. Also Khoosf and Khosravani [12] stated that dispensed with time- and location- constraints, electronic portfolios simplify and vivify the feedback-giving process for teachers and peers in a dramatic way. Otherwise Lorenzo and Ittelson [14] stated that electronic portfolios encouraged personal reflections and often involve the exchanges of ideas and feedback. But in traditional environment, teacher candidates considered that they are unable to benefit from the constructive criticisms and comments from peers in other groups. Additionally they stated lesser feedback from the teacher in the classroom in a limited time.

For sharing they stated the opportunity of being able to sharing videos. However when they thought if they studied in a blog environment, they especially pointed out lack of loading videos and the necessity of uploading link. So they considered that sharing various types of files in facebook environment is easier than blog. Knight, Hakel and Gromko [13] expressed that digital environment allow the products to take such forms as images, sound files, video clips, and so forth. Also teacher candidates considered that the facebook is up one's alley for products that prepared in portfolio, because the products do not break and photographs can be shared easily so the storage of the products and sheltering portfolio are easy. Also Heath [10] pointed out that electronic portfolios such as in facebook enable students to collect, store, and manage their artefacts in a relatively easy and efficient manner, so long as internet access is available. Otherwise they expressed that sharings can be downloaded to the computer at any time and place and examined in detailed. Comparing to the facebook, in traditional they pointed out that they could not see the entire work at any time and place.

On the other hand for security, in facebook environment it was a closed group and they mentioned about the feeling of having a special place and they considered no risk of being stolen of their products out of their class. . Likewise Challis [7] stated the necessity of security and the privacy of students' products. In addition they especially stated that they inspired and developed self-confidence and creativity by seeing other materials. Similarly Khoosf and Khosravani [12] signed that portfolios can help make the learning process more visible to students, developing their capacity for reflection and self-assessment, and thus enabling them gradually to assume more and more responsibility for their own learning. In this way, it serves as a tool for promoting the development of learner autonomy. Likewise Voigt [20] expressed that the feeling of ownership or 'being in control' of one's portfolio provides students with the time necessary for authentic self-development planning and the trust required for critical comments, knowing that they will remain private. But in contrast for traditional environment, they signed that peers in other groups could see products only in class in a limited time and all files are formed could be seen at the end of the semester. Also they stated the less opportunity to see products by many students at the same time and teachers have the limited time to check out.

For following they expressed the facility of following the studies and products in case of absence, instant notifications of sharings and comments. Also they considered that they have a rich portfolio and archive to benefit in their teaching life. Regarding these ideas, Hung [11] founds in his washback e-portfolio study that e-portfolio assessments generate positive washback effects on learning, including building a community of practice, facilitating peer learning, enhancing learning of content knowledge, promoting professional development, and cultivating critical thinking. In contrast the most of advantages of facebook, they experienced the risk of wear and loss and the problem of storage in the traditional environment.

For other cognitive experiences, they considered in facebook, there is no limit for design because of no portability problem of products. They thought that they benefited to develop the abilities of computer literacy and there is no chance for this in traditional environment. Some of teacher candidates expressed that they felt that they are exposed to an application backward away from technology. In contrast, teacher candidates mentioned about some positive sides of the traditional environment though they are less. For comments, they stated that there are no lower level comments as in facebook. For following, they thought that they have a concrete archive at one's hand and for this reason, accessibility is easy compared to facebook. In addition they expressed the memorability and detailed check over facilities. Also they pointed out the sense of real feelings and thoughts, increased socialization, friendship and awareness of duty and responsibility.

Otherwise, teacher candidates expressed lesser negative 
and limited sides of the facebook environment compared to traditional environment as portfolio experiences. These negative and limited sides are related to communication, comments, following, sharing, communication and distribution experiences. For communication they expressed that the negative comments are reduced students interest to the portfolio preparation, lack of access when the net connection problem occurred. For comments, they mentioned about bias comments and being thrilled of teacher's following. For following, they expressed the necessity of remembering and knowledge of using. For sharing they especially mentioned about the error problem in uploading file above a certain capacity and decreased resolution of the products' photographs whenloaded.

Furthermore, they stated the reasons for choosing the environment in another study at a time. Most of them chose facebook because of having a facebook page and knowing how to use. They stated the blog environment is not familiar as facebook. Facebook is constantly updated and improved. Besides that they stressed the security in a closed group, frequently entering because of shortcut in the smart phones so quick accession. They thought that it is easy to make and reach criticism, also instant feedbacks via comments and like buttons.

Hung ([11] cited by [4]) conclude an e-portfolio provides more advantages than a regular portfolio. The advantages sides of the e-portfolios are based on learning outcomes, digital environments, virtual identities, authentic audiences, reflective artifacts, integration, responsibility and longitudinal learning. In addition an e-portfolio provides a personal space on the computer that can be used to brainstorm, write drafts, share artifacts, give and receive feedback, store materials and access sources immediately[1].

The portfolio experiences in facebook closed group may continue to be investigated in teacher education. The levels of students' responsibilities, self-confidence and communication in portfolio experiences may be investigated in various environments such as web 2.0 tools. Some applications of portfolio in web environment, in other words e-portfolio, can be drilled down the essence of the portfolio experiences. The relation of achievement and portfolio experiences in various environments can be examined.

\section{Note}

*The abstract of this paper was presented at 2nd International Conference on Lifelong Learning and Leadership for All (ICLEL-16), in Liepaja on July, 21-23, 2016.

\section{REFERENCES}

[1] Aydin, S. (2014). EFL writers' attitudes and perceptions toward F-portfolio use. TechTrends, 58 (2), 59-77. Barrett, H.C, April 2000, Create Your Own Electronic Portfolio, Retrieved January 03, 2003 from :

http://www.electronicportfolios.com/portfolios/iste2k.html
[2] Barrett, H. C. (2000). Create your own electronic portfolio. Learning \& Leading with Technology, 27(7),15-21.

[3] Barrot, J. S. 2016. Using Facebook-based e-portfolio in ESL writing classrooms: impact and challenges. Language, Culture and Curriculum, DOI: 10.1080/07908318.2016.1143481.

[4] Baturay, M. H., \& Daloğlu, A. (2010). E-portfolio assessment in an online English language course. Computer Assisted Language Learning, 23 (5), 413-428. Retrieved December 20, 2011, from

http://www.tandfonline.com/doi/pdf/10.1080/09588221.201 0.520671

[5] Brown, C. A. (2004). Design, Development, and Evaluation of Electronic Portfolios for Advanced Degree Programs in Technology and School Media. Association for Educational Communications and Technology, 27th, October 19-23, 2004, Chicago.

[6] Carliner, S. (2005). Commentary: Assessing the Current Status of Electronic Portfolios. Canadian Journal of Learning and Technology, 31,3 .

[7] Challis, D. (2005). Towards the mature e-portfolio: Some implications for higher education. Canadian Journal of Learning and Technology, 31(3), online version.

[8] Creswell, J. W. (2016). Qualitative Research Design: Qualitative research and research design based on five approaches, translator eds. M. Butun ve S. B. Demir. Ankara: Siyasal Publishing.

[9] Erdoğan, T. Yurdabakan, İ. (2011). Secondary School Students' Opinions on Portfolio Assessment in EFL. International Journal on New Trends in Education and Their Implications, 2(3), 63-68.

[10] Heath, M. (2002). Electronic portfolios for reflective self-assessment. Teacher Librarian, 30(1),19-23.

[11] Hung, S. A. (2012). A washback study on e-portfolio assessment in an English as a Foreign Language teacher preparation program. Computer Assisted Language Learning, 25(1), 21-36.

[12] Khoosf, S. G., Khosravani, M. (2014). Introducing E-mail Portfolio as a Means of Developing EFL Learner's Autonomy. Procedia-Social and Behavioral Sciences, 98: 504-512.

[13] Knight, W. E., Hakel, M. D. , Gromko, M. (2008). The relationship between electronic portfolio participation and student success. Association for Institutional Research, 107(Spring), 1-16.

[14] Lorenzo,G.Ittelson,J.(2005). An Overview of E-portfolios. Educase Learning Initiative.

https://net.educause.edu/ir/library/pdf/eli3001.pdf

[15] Mobarhan, R. Alhazmi, A. K., Rahman, A. A., Majidi, M. (2014). Why students use electronic portfolio: From uses and gratification perspective. PACIS 2014 Proceedings. Paper 112.

[16] Paulson, F. L. Paulson, P. R. Meyer, C. A. (1991). What Makes a Portfolio a Portfolio? Educational Leadership. 48(5):60-63.

[17] Statista (2016). Number of monthly active Facebook users worldwide as of 1 st quarter 2016 (in millions) http://www.statista.com/statistics/264810/number-of-monthl y-active-facebook-users-worldwide/ 
[18] Tengiz, F. İ. Süral, Y. S. (2016). A portfolio study with the students of medical documentation and secretariat. Medical Education in The World. 45: 28-34.

[19] Tosh, D., Light, T. P., Fleming, K., \& Haywood, J. (2005). Engagement with electronic portfolios: Challenges from the student perspective. Canadian Journal of Learning and Technology, 31 (3).
[20] Voigt, C. (2009). A question of purpose: Community embedded ePortfolios. In same places, different spaces. Proceedings ascilite Auckland 2009.

http://www.ascilite.org.au/conferences/auckland09/procs/voi gt.pdf

[21] Yildirim, A., Simsek, H.( 2011). Research methods in social sciences. Ankara: Seckin Publishing. 